\title{
Maternal-fetal outcome associated with adolescent pregnancy in a tertiary referral center: a cross-sectional study
}

\author{
Evrim Bostancı Ergen, Cigdem Abide Yayla, Enis Ozkaya, Cetin Kilicci, \\ Ilhan Sanverdi, Canan Kabaca Kocakusak
}

Zeynep Kamil Maternity/Children Education and Training Hospital, Üsküdar-Istanbul, Turkey

\begin{abstract}
Objectives: This study was conducted to compare pregnancy outcomes of early-middle adolescent, late adolescent and adult women.

Material and methods: The study focused on early-middle adolescent $(n=145)$, late adolescent $(n=1655)$ and adult ( $n=1585$ ) women who gave birth during 2014 through 2017, utilizing data obtained from the Zeynep Kamil Women and Children's Health Training and Research Hospital. Pregnancy outcomes were determined according to the rates of pregnancy complications, including method of delivery, birth weight, as well as the rate of newborn intensive care admissions. Results: Comparisons between the studied groups for various pregnancy complications showed highest rates of preterm deliveries (PD), preterm premature rupture of membranes (PPROM) and neonatal intensive care unit admission in early-middle adolescent group, whereas the highest cesarean section rates were observed in the adult group $(p<0.001)$.

Conclusions: Analysis of the data revealed that adolescent pregnancy, especially the early-middle adolescent pregnancies, is associated with increased risks of adverse pregnancy outcomes.
\end{abstract}

Key words: adolescent, pregnancy, preeclampsia, preterm delivery, pregnancy complications

Ginekologia Polska 2017; 88, 12: 674-678

\section{INTRODUCTION}

Pregnant women in developing countries are on average younger than their Western counterparts and, furthermore, $11 \%$ of all births were reported to be given by adolescent mothers [1]. Maternal and neonatal deaths are the most powerful indicators of health care in a given country; therefore, due to the higher rate of observed deaths (25\%) in adolescent mothers, this group should be considered the reference population for the establishment of effective health care policies [1]. These early age pregnancies were shown to result in higher rates of pregnancy complications, such as low birth weight (LBW), preterm delivery (PD), small-for-gestational-age (SGA) infants, perinatal death, eclampsia, operative vaginal delivery, and maternal death [2]. A recent study reported the pregnancy outcomes of women of early adolescent age; the authors indicated that early adolescent pregnancies are associated with higher risks of preterm birth and growth restriction, while the other maternal morbidities were shown to be similar to the control groups. Unexpectedly, the cesarean section rate was significantly lower in early adolescent mothers [3]. In contrast, recent data obtained from 144 countries indicated that, "excess mortality risk to adolescent mothers might be less than previously believed, and in most countries the adolescent maternal mortality ratio is low when compared with women older than 30 years" [4]. In this study, adolescence has been investigated as, and categorized into, three stages: early (11-13 years old), middle (14-16 years old) and late adolescence (17-19 years old) [5].

\section{OBJECTIVES}

This study was conducted in effort to compare specific pregnancy complications with relation to the maternal-fetal outcome of early-middle adolescent, late adolescent and adult women. 


\section{MATERIAL AND METHODS}

The data in this study consists of perinatal clinical records compiled from women of Turkish ethnic group, who gave birth during 2014 through 2017, further categorized as early-middle adolescent $(n=145)$, late adolescent $(n=1655)$ and adult $(n=1585)$. The data was obtained from the hospital database of the Zeynep Kamil Women and Children's Health Training and Research Hospital. Inclusion in the study group was solely restricted to women between 13 and 21 years of age (mean: 17.9 years) who had a singleton birth of at least 20 weeks' gestation or a minimum birth weight of $400 \mathrm{~g}$.

Maternal age was defined as the completed age of the mother (in years) at the time of delivery and was further categorized into 3 groups: early-middle adolescence (between 13 and 16 years of age), late adolescence (between 17 and 19 years of age), and adult (between 20-21 years of age). The adult classification was considered to be the control group.

Gestational age at birth was calculated as number of weeks from the first day of the last menstrual cycle until the delivery date. Adverse maternal outcomes were determined according to various pregnancy complications, i.e. preeclampsia, cesarean delivery (CS), anemia, preterm premature rupture of membranes (PPROM), preterm delivery (PD), and intrauterine growth restriction (IUGR). Maternal morbidity is defined as the death of a woman while pregnant or within 42 days after delivery from any cause related to, or aggravated by, the pregnancy or its management. The variables used to determine the perinatal outcomes were LBW (birth weight $<2500 \mathrm{~g}$ at birth), very LBW (birth weight $<1500 \mathrm{~g}$ at birth), PD (deliveries before 37 weeks'gestation), small for gestational age (birth weight $<10^{\text {th }}$ percentile at birth), fetal death (delivery of infant at or after 20 weeks' gestation without cardiac activity). Rates of adverse pregnancy outcomes were calculated for each maternal age group. Estimates of crude odds ratio (OR) with a $95 \% \mathrm{Cl}$ were computed as measures of association between each maternal age group and considered adverse pregnancy outcomes. Adjusted ORs were derived through the use of logistic regression models. The estimates were adjusted for the following potential confounding factors: the number of antenatal visits and the hemoglobin concentration at first visit. All analyses were performed with the SPSS 8.0 program package (SPSS Inc, Chicago, III). Mann Whitney-U test or independent samples-t test were used to compare continuous variables, chi square test was used to compare categorical variables and binary logistic regression analyses were used to calculate the adjusted odds ratios.

\section{RESULTS}

There were 145 individuals in the early adolescent group, the late adolescent group consisted of 1655 individuals and the remaining 1585 women constituted the adult pregnant group. Comparison of the 3 groups showed significant differences in terms of demographic and clinical parameters, including: age, gestational age at delivery, number of prenatal visits and hemoglobin level at initial visit $(p<0.001$, Table 1). Comparison of groups for pregnancy complications showed the highest rate of PD, PPROM and neonatal intensive care unit admission (NICU) in the early-middle adolescent category, whereas the highest cesarean rates were observed in adult group ( $p<0.001$, Table 2). Table 3 illustrates the adjusted and unadjusted odds ratios for each specific complication observed within each category and relative to the aforementioned age group classifications (early-middle adolescent, late adolescent and adult). There was no maternal death observed during the study period.

Table 1. Comparison of some demographic and clinical characteristics among early-middle adolescent, late adolescent and adult groups

\begin{tabular}{|c|c|c|c|c|c|c|c|}
\hline & & $\mathbf{N}$ & Mean & Std. deviation & Minimum & Maximum & $P$ value \\
\hline \multirow{3}{*}{ Maternal age (years) } & EA & 145 & 15.600 & 0.6 & 13.0 & 16.0 & \multirow{3}{*}{$<0.001$} \\
\hline & LA & 1655 & 18.379 & 0.7 & 17.0 & 19.0 & \\
\hline & A & 1585 & 20.245 & 0.4 & 20.0 & 21.0 & \\
\hline \multirow{3}{*}{$\begin{array}{l}\text { Gestational age at delivery } \\
\text { (weeks) }\end{array}$} & EA & 145 & 36.828 & 29.7 & 22.0 & 42.0 & \multirow{3}{*}{$<0.001$} \\
\hline & LA & 1655 & 37.506 & 24.6 & 23.0 & 42.0 & \\
\hline & A & 1585 & 38.158 & 23.7 & 22.0 & 43.0 & \\
\hline \multirow{3}{*}{ \# of prenatal visit } & EA & 145 & 3.000 & 22.9 & 1.0 & 13.0 & \multirow{3}{*}{$<0.001$} \\
\hline & LA & 1655 & 4.783 & 39.3 & 1.0 & 42.0 & \\
\hline & A & 1585 & 5.548 & 42.1 & 1.0 & 37.0 & \\
\hline \multirow{3}{*}{$\begin{array}{l}\text { Hemoglobin concentration } \\
\text { at first visit }[\mathrm{g} / \mathrm{dL}]\end{array}$} & EA & 145 & 9.769 & 12.7 & 7.0 & 13.0 & \multirow{3}{*}{$<0.00$} \\
\hline & LA & 1655 & 10.083 & 13.5 & 6.0 & 15.0 & \\
\hline & A & 1585 & 9.954 & 12.1 & 5.0 & 14.0 & \\
\hline
\end{tabular}

EA — early adolescent; LA — late adolescent; $A$ - adult 
Table 2. Comparison of some pregnancy complications and outcome among early-middle adolescent, late adolescent and adult groups

\begin{tabular}{|l|c|c|c|c|}
\hline \multirow{2}{*}{ Outcome } & \multicolumn{4}{|c|}{ Maternal age } \\
\cline { 2 - 5 } & Early adolescent (\%) & Late adolescent (\%) & Adult (\%) & P value \\
\hline Preeclampsia & 4.8 & 2.7 & 5.9 & $<0.001$ \\
\hline PD & 37.2 & 12.8 & 2.2 & $<0.001$ \\
\hline PPROM & 37.2 & 10.2 & 8.5 & $<0.001$ \\
\hline IUGR & 9 & 3.3 & 5.4 & $<0.001$ \\
\hline NICU & 18 & 11.7 & 10 & 0.009 \\
\hline Postterm & 0.7 & 5.9 & 8.7 & $<0.001$ \\
\hline Episiotomy & 79.3 & 69.8 & 70 & $>0.05$ \\
\hline Neonatal outcome & 2.1 & 1.1 & 2.1 & $>0.05$ \\
\hline LBW & 17.9 & 13.2 & 13.1 & $>0.05$ \\
\hline VLBW & 4.1 & 3.4 & 2.7 & $>0.05$ \\
\hline C/S & 17.2 & 25.7 & 29.6 & 0.001 \\
\hline
\end{tabular}

PD — preterm delivery; PPROM — preterm premature rupture of membranes; IUGR — intrauterine growth restriction; NICU — neonatal intensive care unit admission; LBW - low birth weight; VLBW - very low birth weight; C/S - Caesarean section

Table 3. Summary of adjusted and unadjusted comparisons of odds ratios for each assessed pregnancy complication

\begin{tabular}{|c|c|c|c|c|c|}
\hline & \multicolumn{5}{|c|}{ Maternal age } \\
\hline & Early adolescent & Late adolescent & Adult & $P$ value & $\mathbf{P}^{*}$ \\
\hline Preeclampsia & $\begin{array}{l}1.14(0.52-2.5) \\
1.2(0.5-2.6)^{*}\end{array}$ & $\begin{array}{c}0.44(0.31-0.63 \\
0.4(0.3-0.6)^{*}\end{array}$ & $\begin{array}{l}2.1(1.51-3.01) \\
2.1(1.5-3)^{*}\end{array}$ & $<0.001$ & $<0.001$ \\
\hline Preterm & $\begin{array}{c}7.19(5.01-10.3) \\
6.9(4.8-9.9)^{*}\end{array}$ & $\begin{array}{l}2.7(2.1-3.5) \\
2.6(2.1-3.4)^{*}\end{array}$ & $\begin{array}{c}0.13(0.09-0.19) \\
0.1(0.09-0.2)^{*}\end{array}$ & $<0.001$ & $<0.001$ \\
\hline PPROM & $\begin{array}{l}5.7(4.1-8.2) \\
5.9(4.2-8.6)^{*}\end{array}$ & $\begin{array}{l}0.92(0.74-1.1) \\
0.9(0.7-1.2)^{*}\end{array}$ & $\begin{array}{c}0.66(0.52-0.83) \\
0.7(0.5-0.8)^{*}\end{array}$ & $<0.001$ & $<0.001$ \\
\hline IUGR & $\begin{array}{l}2.2(1.2-3.9) \\
2.5(1.4-4.6)^{*}\end{array}$ & $\begin{array}{c}0.61(0.42-0.83) \\
0.6(0.4-0.8)^{*}\end{array}$ & $\begin{array}{l}1.5(1.1-2.1) \\
1.4(1.1-2.1)^{*}\end{array}$ & $>0.05$ & $>0.05$ \\
\hline $\mathrm{NICU}$ & $\begin{array}{l}1.8(1.2-2.8) \\
1.8(1.2-2.9)^{*}\end{array}$ & $\begin{array}{l}1.1(0.9-1.4) \\
1.1(0.9-1.4)^{*}\end{array}$ & $\begin{array}{c}0.8(0.6-1) \\
0.8(0.6-1)^{*}\end{array}$ & 0.009 & 0.004 \\
\hline Post-term & $\begin{array}{c}0.1(0.001-0.6) \\
0.08(0.01-0.6)^{*}\end{array}$ & $\begin{array}{l}0.7(0.5-0.9) \\
0.7(0.6-0.9)^{*}\end{array}$ & $\begin{array}{c}1.6(1.2-2.1) \\
1.6(1.3-2.1)^{*}\end{array}$ & $<0.001$ & $<0.001$ \\
\hline Episiotomy & $\begin{array}{l}1.6(1.1-2.4) \\
1.6(1.1-2.4)^{*}\end{array}$ & $\begin{array}{l}0.9(0.8-1.1) \\
0.9(0.8-1.1)^{*}\end{array}$ & $\begin{array}{l}0.9(0.8-1.1) \\
1.1(0.9-1.2)^{*}\end{array}$ & $>0.05$ & $>0.05$ \\
\hline Neonatal outcome & $\begin{array}{l}1.2(0.4-3.8) \\
1.7(0.4-7.4)^{*}\end{array}$ & $\begin{array}{c}0.6(0.4-1) \\
0.7(0.4-1.4)^{*}\end{array}$ & $\begin{array}{c}1.4(0.9-2.5) \\
1.3(0.7-2.5)^{*}\end{array}$ & $>0.05$ & $>0.05$ \\
\hline LBW & $\begin{array}{l}1.4(0.9-2.3) \\
1.5(0.9-2.4)^{*}\end{array}$ & $\begin{array}{c}0.9(08-1.1) \\
0.9(0.8-1.1)^{*}\end{array}$ & $\begin{array}{c}0.9(08-1.1) \\
0.9(0.8-1.2)^{*}\end{array}$ & $>0.05$ & $>0.05$ \\
\hline VLBW & $\begin{array}{c}1.3(0.6-3.1) \\
1.5(0.6-3.7)^{*}\end{array}$ & $\begin{array}{l}1.2(0.8-1.8) \\
1.3(0.9-2)^{*}\end{array}$ & $\begin{array}{l}0.8(0.5-1.1) \\
0.7(0.4-1)^{*}\end{array}$ & $>0.05$ & $>0.05$ \\
\hline $\mathrm{C} / \mathrm{S}$ & $\begin{array}{l}0.5(0.3-0.8) \\
0.6(0.4-0.9)^{*}\end{array}$ & $\begin{array}{l}0.9(0.7-1) \\
0.9(0.8-1)^{*}\end{array}$ & $\begin{array}{l}1.3(1.1-1.4) \\
1.2(1.1-1.4)^{*}\end{array}$ & 0.001 & 0.004 \\
\hline
\end{tabular}

*Number of prenatal visits and first trimester hemoglobin concentration adjusted odds ratios and $\mathrm{P}$ values. Odds ratios for specific group relative to the other two. PD — preterm delivery; PPROM — preterm premature rupture of membranes; IUGR — intrauterine growth restriction; NICU — neonatal intensive care unit admission LBW - low birth weight; VLBW - very low birth weight; C/S - Caesarean section

\section{DISCUSSION}

In this study, we aimed to compare the maternal-fetal outcome of women in different age groups. Most previous pregnancy studies aimed to compare between the significantly broader classification of adolescent and adult women.
There are few studies comparing pregnancy outcomes that encompass subgroups such as early-middle, late adolescents and adult women. Our data analyses revealed that, early-middle adolescent pregnancies had higher risk for poor pregnancy outcome, especially with complications related with 
PD, PPROM and the rate of NICU admission. Despite higher rates of some pregnancy complications, our study found significantly lower CS rates in the early-middle adolescent age group. A similar conclusion was drawn from a Turkish study which was conducted in 2005; the authors showed significantly lower CS rates in this group of women - reported to be and incidence of $17 \%$ in their study [6]. Adolescent women with adequate prenatal care (at least $>2$ antenatal visits) were reported to be at no greater risk of experiencing adverse obstetric outcomes than their adult counterparts of a similar socio-demographic background [7]. Although the early-middle adolescent mothers in this study had a mean of 3 prenatal visits, this value was significantly lower as compared to the control group. As a result, after adjusting for the number of prenatal visits, we observed similar statistically significant differences with regard to the preterm, post-term deliveries, preeclampsia, and cesarean, neonatal intensive care unit admissions rates. This result indicated the existence of other confounding variables responsible for the poor outcome observed in this group. In the literature, some specific pregnancy complications have been reported which observed higher frequencies in adolescent mothers, such as: episiotomies, operative vaginal deliveries, and puerperal endometritis [8,9]. Therefore, some pathophysiological mechanisms have been proposed - the pelvic bones and the birth canal were suggested to be in the process of growth, which may lead to the increased risk of prolonged and obstructed labor, episiotomy, use of forceps and/or ventouse, and puerperal endometritis [10]. According to this theory, it is generally expected to see higher cesarean section rates in these women as seen in previous studies [10-12]; however, consistent with the previous studies $[6,13,14]$, our data revealed a $17 \%$ cesarean section rate in the early-middle adolescent group that was significantly lower as compared to the other groups. Although the study observed a higher rate of PD in early-middle adolescent groups, LBW incidence was similar among groups. In the literature, there are some reports indicating similar pregnancy outcomes in adolescent pregnancies as compared to the other age groups [15]. Nonetheless, the majority of the studies show consistency for the increased risk of PD in the adolescent age group [6, 17]. There are also some conflicting results with regard to the risk of neonatal mortality among infants born to adolescent mothers [18]. Our study showed similar neonatal mortality rates among three groups. A myriad of socioeconomic factors have been proposed for the increased risk of poor pregnancy outcome in early age group - including inadequate prenatal care, poverty, unmarried status, low educational levels, psychological stress, and illicit drug use $[12,6]$. Some studies indicated the age to be the main determinant for the increased risk, independent from the previously discussed socioeconomic factors $[10,11,17,18]$. It was speculated that the growing body requirements of an adolescent mother may lead to competition between the mother and fetus $[2,17]$. A few authors made it evident that factors such as low pre-pregnancy weight and height, parity, contracted pelvis, and low pregnancy weight gain appear to be frequent findings in the adolescent group, which may lead to an increased rate of poor pregnancy outcome [2]. Another report confirmed this hypothesis and suggested that pregnancy among adolescents was not associated with worse maternal outcomes, but is associated with worse perinatal outcomes - these findings were prominent in younger adolescents. Also they concluded that an increased risk of worse perinatal outcome might be due to biological immaturity rather than socio-economic factors, such as inadequate antenatal or delivery care [19]. In contrast, our study population showed a significantly lower mean number of antenatal visits in the early adolescent group; statistical adjustment for the number of prenatal visits did not account for the differences among the groups. Due to the aforementioned complications associated with adolescent pregnancy, pregnancy prevention strategies and the improvement of healthcare interventions were proposed to be the main focus in effort to reduce adverse pregnancy outcomes among adolescent women residing in low- and middle-income countries [20]. Another study suggested the use of adequate prenatal care for the prevention of some adverse perinatal outcomes among adolescents [21].

\section{CONCLUSIONS}

Our data confirmed that adolescent pregnancy, especially the early-middle adolescent pregnancies, are independently associated with increased risks of adverse pregnancy outcomes while adjustment for the number of prenatal visits resulted in similar statistically significant differences. Our data showed higher complication rates in the early-middle adolescent group independent from the number of prenatal visits. Further studies are required to indicate pregnancy complications specific for this group and in effort to determine measurable and adjustable variables to obtain better outcomes.

\section{Acknowledgements}

None

\section{REFERENCES}

1. World Health Organization. WHO Guidelines on Preventing Early Pregnancy and Poor Reroductive Outcomes: WHO; p.9 2011.

2. Black AY, Fleming NA, Rome ES. Pregnancy in adolescents. Adolesc Med State Art Rev. 2012; 23(1): 123-138.

3. Traisrisilp K, Jaiprom J, Luewan S, et al. Pregnancy outcomes among mothers aged 15 years or less. J Obstet Gynaecol Res. 2015; 41(11): 1726-1731, doi: 10.1111/jog.12789, indexed in Pubmed: 26311210.

4. Nove A, Matthews Z, Neal S, et al. Maternal mortality in adolescents compared with women of other ages: evidence from 144 countries. Lancet Glob Health. 2014; 2(3): e155-e164, doi: 10.1016/S2214-109X(13)70179-7, indexed in Pubmed: 25102848.

5. Lempers JD, Clark-Lempers DS. Young, middle, and late adolescents comparisons of the functional importance of five significant relation- 
ships. J Youth Adolesc. 1992; 21(1): 53-96, doi: 10.1007/BF01536983, indexed in Pubmed: 24263682.

6. Zeteroglu S, Sahin I, Gol K. Cesarean delivery rates in adolescent pregnancy. Eur J Contracept Reprod Health Care. 2005; 10(2): 119-122, doi: 10.1080/13625180500131600, indexed in Pubmed: 16147817.

7. Bukulmez O, Deren O. Perinatal outcome in adolescent pregnancies: a case-control study from a Turkish university hospital. Eur J Obstet Gynecol Reprod Biol. 2000; 88(2): 207-212, doi: 10.1016/s0301-2115(99)00145-1, indexed in Pubmed: 10690683.

8. Anandalakshmy PN, Buckshee K. Teenage pregnancy and its effect on maternal and child health--a hospital experience. Indian J Med Sci. 1993; 47(1): 8-11, indexed in Pubmed: 8514342.

9. Zabin LS, Kiragu K. The health consequences of adolescent sexual and fertility behavior in sub-Saharan Africa. Stud Fam Plann. 1998; 29(2): 210-232, doi: 10.2307/172160, indexed in Pubmed: 9664633.

10. Jolly MC, Sebire N, Harris J, et al. Obstetric risks of pregnancy in women less than 18 years old. Obstet Gynecol. 2000; 96(6): 962-966, doi: 10.1016/s0029-7844(00)01075-9, indexed in Pubmed: 11084186.

11. Satin AJ, Leveno KJ, Sherman ML, et al. Maternal youth and pregnancy outcomes: middle school versus high school age groups compared with women beyond the teen years. Am J Obstet Gynecol. 1994; 171(1): 184-187, doi: 10.1016/0002-9378(94)90467-7, indexed in Pubmed: 8030697.

12. Smith GC, Pell JP. Teenage pregnancy and risk of adverse perinatal outcomes associated with first and second births: population based retrospective cohort study. BMJ. 2001; 323(7311): 476, doi: 10.1136/bmj.323.7311.476, indexed in Pubmed: 11532837.

13. Conde-Agudelo A, Belizán JM, Lammers C. Maternal-perinatal morbidity and mortality associated with adolescent pregnancy in Latin America: Cross-sectional study. Am J Obstet Gynecol. 2005; 192(2): 342-349, doi: 10.1016/j.ajog.2004.10.593, indexed in Pubmed: 15695970.
14. Keskinoglu P, Bilgic $N$, Picakciefe $M$, et al. Perinatal outcomes and risk factors of Turkish adolescent mothers. J Pediatr Adolesc Gynecol. 2007; 20(1): 19-24, doi: 10.1016/j.jpag.2006.10.012, indexed in Pubmed: 17289512.

15. Olausson PM, Cnattingius S, Goldenberg RL. Determinants of poor pregnancy outcomes among teenagers in Sweden. Obstet Gynecol. 1997; 89(3): 451-457, doi: 10.1016/s0029-7844(97)00009-4, indexed in Pubmed: 9052604.

16. Phipps MG, Sowers M. Defining early adolescent childbearing. Am J Public Health. 2002; 92(1): 125-128, doi: 10.2105/ajph.92.1.125, indexed in Pubmed: 11772775.

17. Fraser AM, Brockert JE, Ward RH. Association of young maternal age with adverse reproductive outcomes. N Engl J Med. 1995; 332(17): 1113-1117, doi: 10.1056/NEJM199504273321701, indexed in Pubmed: 7700283.

18. Olausson $P, C$ nattingius $S$, Haglund $B$. Teenage pregnancies and risk of late fetal death and infant mortality. BJOG. 1999; 106(2): 116-121, doi: 10.1111/j.1471-0528.1999.tb08210.x.

19. Althabe $F$, Moore $\mathrm{L}$, Gibbons $L$, et al. Adverse maternal and perinatal outcomes in adolescent pregnancies: The Global Network's Maternal Newborn Health Registry study. Reprod Health. 2015; 12 Suppl 2: S8, doi: 10.1186/1742-4755-12-S2-S8, indexed in Pubmed: 26063350.

20. Ganchimeg T, Ota E, Morisaki N, et al. WHO Multicountry Survey on Maternal Newborn Health Research Network. Pregnancy and childbirth outcomes among adolescent mothers: a World Health Organization multicountry study. BJOG. 2014; 121 Suppl 1:40-48, doi: 10.1111/14710528.12630, indexed in Pubmed: 24641534.

21. Minjares-Granillo RO, Reza-López SA, Caballero-Valdez S, et al. Maternal and Perinatal Outcomes Among Adolescents and Mature Women: A Hospital-Based Study in the North of Mexico. J Pediatr Adolesc Gynecol. 2016; 29(3): 304-311, doi: 10.1016/j.jpag.2015.11.005, indexed in Pubmed: 26620384 